\title{
Prognostic Impact of Intraoperative Blood Loss in Liver Transplant Patients with Advanced Hepatocellular Carcinoma
}

\author{
ARNO KORNBERG ${ }^{1}$, ULRIKE WITT ${ }^{1}$, JENNIFER KORNBERG $^{2}$, GÜRALP O. CEYHAN $^{1}$, \\ KATHARINA MUELLER ${ }^{3}$, HELMUT FRIESS ${ }^{1}$ and KATHARINA THRUM ${ }^{4}$ \\ ${ }^{1}$ Department of Surgery, University Hospital Rechts der Isar, Technical University Munich, Munich, Germany; \\ ${ }^{2}$ Department of Anaesthesiology, University Hospital Großhadern, \\ Ludwig Maximilian University Munich, Munich, Germany; \\ ${ }^{3}$ Department of Surgery, University of Jena, Jena, Germany; \\ ${ }^{4}$ Institute of Pathology, Helios Hospital Berlin, Berlin, Germany
}

\begin{abstract}
Background/Aim: The aim of this retrospective study was to analyze the impact of intraoperative blood loss (IOBL) on outcome in liver transplant (LT) patients with advanced hepatocellular carcinoma (HCC). Patients and Methods: A total of 108 LT patients with HCC were retrospectively analyzed. They were all clinically staged according to the Milan criteria and to ${ }^{18} F$-fluoro-D-glucose $\left({ }^{18} \mathrm{~F}-F D G\right)$ uptake on positron-emission tomography (PET). Results: Recurrence-free survival rates at 3 and 5 years postLT were $91.9 \%$ and $91.9 \%$ among patients with low $(\leq 1,500$ $\mathrm{ml}) \mathrm{IOBL}$, and $43.9 \%$ and $37.1 \%$ in those with high $(>1,500$ ml) IOBL (log-rank $p<0.001)$. Multivariate analysis demonstrated low IOBL to be an independent predictor of better recurrence-free survival in patients with $\mathrm{HCC}$ exceeding the Milan criteria (hazard ratio=3.66; $p=0.029$ ) and in those with PET-positive tumors (hazard ratio=4.13; $p=0.007)$. Conclusion: Intraoperative bleeding is associated with increased likelihood of tumor recurrence following $L T$ for HCC. Limiting IOBL should be considered for improving post-LT outcome, particularly in patients with HCC beyond standard criteria.
\end{abstract}

Only about $30 \%$ of patients diagnosed with hepatocellular carcinoma (HCC) in liver cirrhosis are candidates for

Correspondence to: Arno Kornberg, MD, Ph.D., Department of Surgery, Klinikum Rechts der Isar, Technical University Munich, Ismaningerstr. 22, D-81675 Munich Germany. Tel: +49 08941402011 , Fax: +49 08941404884, e-mail: ArnoKornberg@aol.com

Key Words: Liver transplantation, hepatocellular carcinoma, intraoperative blood loss, Milan criteria, ${ }^{18} \mathrm{~F}-\mathrm{FDG}$ positron-emission tomography, survival. curative surgical therapy. Unfortunately, tumor relapse is still a significant problem, with $\mathrm{HCC}$ recurrence rates above 50\% after liver resection $(1,2)$ and between $10 \%$ and $25 \%$ following liver transplantation (LT) $(3,4)$.

Recurrent HCC post-LT is a particular problem, since it may not only result in death of the organ recipient, but also in loss of a scarce donor graft resource. The adoption of the Milan criteria in 1996 by Mazzaferro et al. (5) dramatically reduced tumor recurrence rates by implementing strict selection criteria based on radiographic tumor size and number (one tumor nodule up to $5 \mathrm{~cm}$, or up to three tumor nodules each not exceeding $3 \mathrm{~cm}$, no macrovascular invasion). From that time onwards, excellent post-transplant overall and recurrence-free survival rates for patients with HCC have been reported that were equivalent to those with non-malignant diseases $(3,6)$. There is accumulating evidence that the Milan criteria are, however, not appropriate for precisely defining oncological risk. Strict adherence to radiographic features of tumor macromorphology was shown to exclude many patients with advanced HCC from undergoing potentially curative LT (3, 7-9). In contrast, expanding the selection criteria based on the size and number of tumor nodules significantly increases the risk of tumor recurrence, as has been demonstrated by the 'metro-ticket concept' $(10,11)$. Therefore, several markers of biological tumor behavior have been studied to improve selection process and transplant benefit. In particular, histopathological variables such as vascular invasion and poor grading were shown to correlate with the risk of post-transplant $\mathrm{HCC}$ recurrence $(3,8,12,13)$. In recent years, ${ }^{18} \mathrm{~F}$-fluoro-D-glucose $\left({ }^{18} \mathrm{~F}\right.$-FDG) positronemission tomography (PET) was identified as a useful pretransplant diagnostic tool to indicate aggressive tumor metabolism and poor prognosis (14-16). 
Apart from these tumor-specific variables, non-tumorrelated factors at the time of LT are currently being discussed as affecting HCC recurrence (17). In particular, surgical trauma by ischemia-reperfusion ( $/ / R)$ injury to the graft is purported to promote engraftment of circulating cancer cells and subsequent intra- and extrahepatic tumor outgrowth by induction of pro-inflammatory and oxidative mechanisms (18-21). Recently, prolongation of warm ischemia time was shown to increase the tumor recurrence rate, particularly in patients with HCC exceeding the Milan criteria (22). Therefore, targeting the mechanisms of $\mathrm{I} / \mathrm{R}$ is discussed as a useful clinical approach for improving prognosis in LT patients with advanced HCC.

Severe intraoperative bleeding leads to hypoperfusion and hypoxia of the liver graft, thereby aggravating hepatic $I / R$ damage $(23,24)$. In recent years, intraoperative blood loss (IOBL) was shown to foster HCC relapse after liver resection (25-27). We hypothesized that in the special situation of immunosuppressive treatment, IOBL may have a substantial impact on oncological outcome following LT for HCC, particularly in those exceeding the standard criteria.

In order to address this issue, we conducted a retrospective study to investigate the influence of IOBL on overall and recurrence-free survival in a series of LT patients with HCC. Subgroup analysis was performed according to the radiographic Milan criteria and to ${ }^{18}$ F-FDG uptake on pretransplant PET imaging.

\section{Patients and Methods}

Patients. The study was conducted in accordance with the Declaration of Helsinki and approved by the Local Ethics Authority (22/16 S). We identified a total of 111 patients from our prospective database that underwent LT for HCC between 1996 and 2011. Three patients with early perioperative death were excluded from the data analysis. Diagnosis of HCC was established by radiographic imaging and alpha fetoprotein (AFP) level. In order to avoid risk of tumor cell seeding, we did not perform percutaneous tumor biopsy before LT.

Prior to LT, all patients underwent ${ }^{18} \mathrm{~F}-\mathrm{FDG}$ PET in order to exclude extrahepatic malignancies and to determine the metabolic aggressiveness of HCC. According to the FDG-uptake pattern of $\mathrm{HCC}$ in relation to surrounding normal liver tissue, tumors were semiquantitatively classified as PET-negative (PET ${ }^{-}$, PET status comparable to that of normal liver tissue;) or PET-positive $\left(\mathrm{PET}^{+}\right.$, PET status increased compared to normal liver tissue), as previously described (15).

The Milan criteria were used for registering a patient on the transplant waiting list. After the implementation of the model for end-stage liver disease (MELD) score in December 2006, patients with HCC meeting the Milan criteria received exceptional-priority MELD upgrades. Based on liver function and tumor topography, neoadjuvant locoregional tumor treatment by transarterial chemoembolization (TACE) was performed.

Tumor progression beyond the Milan burden limits resulted in loss of exceptional MELD priority status. Depending on the results of a close tumor surveillance program (including repeat measurements of AFP, computed tomography (CT), magnetic resonance imaging and PET scanning), these patients were primarily scheduled for rescue organ allocation. Fulminant progression, macrovascular infiltration and extrahepatic tumor manifestation were all absolute contraindications for LT.

According to final pretransplant radiographic staging, patients were classified as 'Milan In' (HCC meeting the Milan criteria) or 'Milan Out' (HCC exceeding the Milan criteria).

Histopathological variables of tumor aggressiveness such as grading and microvascular invasion (MVI) were recorded.

Transplant procedure. Liver transplantation was performed by using the piggy back technique without veno-venous bypass. In order to avoid the risk of systemic tumor cell spread, we did not use intraoperative blood salvage autotransfusion. The amount of IOBL was calculated by monitoring the suction container, including the blood volume collected by abdominal sponges and compresses. the number of administered packed red blood cell (RBC) units was recorded. The extent of hepatic $\mathrm{I} / \mathrm{R}$ injury was assessed by determination of peak values of aspartate aminotransferase (AST) and alanine aminotransferase (ALT) during the first postoperative week. Peak post-transplant levels of C-reactive protein (CRP) were assessed to describe the degree of early-phase pro-inflammatory response reaction $(28,29)$.

Post-transplant follow-up. Immunosuppressive treatment consisted of a cyclosporine A- or tacrolimus-based regimen. Prednisolone was tapered within 3 months, except in patients with an autoimmune liver disease. Post-transplant tumor surveillance included determination of AFP level and liver ultrasound every 3 months. In addition, patients underwent $\mathrm{CT}$ scans of the chest and abdomen every 6 months during the first year post-LT and minimum yearly thereafter, or in the case of suspected tumor relapse.

Statistical analysis. Categorical variables are reported as frequencies and percentages. They were compared using the $\chi^{2}$ test. Continuous variables are illustrated as the mean \pm standard deviation or median and range, and compared using Student's $t$-test.

The Kaplan-Meier method was used to determine overall and recurrence-free survival rates and these were compared by the log-rank test. Variables significantly associated with overall and recurrence-free survival on univariate analysis $(p<0.1)$ were entered into a stepwise multivariate Cox regression model with a level of significance set at $p<0.05$. Subgroup analyses were performed according to the Milan criteria (Milan In versus Milan Out) and to the PET status (PETversus $\mathrm{PET}^{+}$). All statistical analyses were performed using the software SPSS 23.0 (IBM Inc., Munich, Germany).

\section{Results}

Patient and tumor characteristics. Clincopathological characteristics of the study cohort are listed in Table I. The majority of patients $(72.2 \%)$ were suffering from viral hepatitis B or C. Sixty-five patients $(60.2 \%)$ were male, and 68 patients $(63 \%)$ underwent TACE prior to LT.

Pretransplant PET studies demonstrated ${ }^{18} \mathrm{~F}$-FDG-avid $\mathrm{HCC}\left(\mathrm{PET}^{+}\right)$in 40 patients $(37 \%)$, while 68 tumors $(63 \%)$ had no increased FDG-uptake ( PET $^{-}$). 
Table I. Clinicopathological parameters $(n=108)$.

\begin{tabular}{lc}
\hline Variable & Value \\
\hline Age of recipient (mean \pm STD), years & $58.6 \pm 6.8$ \\
Male, $\mathrm{n}(\%)$ & $65(60.2 \%)$ \\
Liver disease, n (\%) & \\
Alcoholic & $61(56.5 \%)$ \\
Hepatitis C & $18(16.7 \%)$ \\
Hepatitis B & $12(11.1 \%)$ \\
Autoimmune & $4(3.7 \%)$ \\
Cholestatic & $3(2.8 \%)$ \\
Other & $10(9.3 \%)$ \\
Viral disease, $\mathrm{n}(\%)$ & $30(27.8 \%)$ \\
Child-Pugh B or C, $\mathrm{n}(\%)$ & $57(52.8 \%)$ \\
MELD score at LT (mean \pm STD) & $18.4 \pm 6.2$ \\
Median AFP level at LT (range), ng/ml & $52.5(1.5-46930)$ \\
TACE prior LT, $\mathrm{n}(\%)$ & $68(63 \%)$ \\
Multiple HCC nodules, $\mathrm{n}(\%) *$ & $52(48.1 \%)$ \\
Median maximum HCC nodule size (range), cm* & $3.8(1-20)$ \\
Median total tumor diameter (range), cm* & $6(1-20)$ \\
Median number of HCC nodules (range) & $1(1-8)$ \\
Milan Out status, $\mathrm{n}(\%)^{*}$ & $42(38.9 \%)$ \\
PET ${ }^{*}$ status, $\mathrm{n}(\%)$ & $40(37 \%)$ \\
Donor age (mean \pm STD), years & $50.1 \pm 13.6$ \\
Operative time (mean \pm STD), min & $357.7 \pm 67.3$ \\
Total ischemia time (mean \pm STD), min & $446.9 \pm 121.4$ \\
Intraoperative blood loss (mean \pm STD), ml & $1493 \pm 626.5$ \\
Median number of red blood cell & \\
transfusion units (range) & $4(1-10)$ \\
Microvascular invasion, $\mathrm{n}(\%)$ & $42(38.9 \%)$ \\
Poor tumor differentiation, $\mathrm{n}(\%)$ & $21(19.4 \%)$ \\
Tacrolimus-based immunosuppression, $\mathrm{n}(\%)$ & $58(53.7 \%)$ \\
\hline
\end{tabular}

STD: Standard deviation; MELD: model for end-stage liver disease; LT: liver transplantation; AFP: alpha fetoprotein; TACE: transarterial chemoembolization; HCC: hepatocellular carcinoma; $\mathrm{PET}^{+}$: positronemission tomography-positive. *According to pretransplant radiographic staging.

Final pre-transplant radiographic imaging showed HCC meeting the Milan criteria in $66(61.1 \%)$ and tumors beyond the Milan criteria in 42 patients $(38.9 \%)$, respectively. The majority of patients had multiple tumors (51.9\%).

Explant histopathology demonstrated MVI in 42 (38.9\%) and poor grading in $21(19.4 \%)$ tumor specimen (Table I).

Intraoperative blood loss. The overall mean IOBL was $1,505.8 \mathrm{ml}$ (median=1,400 $\mathrm{ml}$; range $=600$ to $4,000 \mathrm{ml}$ ). The study population was accordingly divided into two subgroups: the low IOBL $(\leq 1,500 \mathrm{ml} ; \mathrm{n}=75 ; 69.4 \%)$ and the high IOBL ( $>1,500 \mathrm{ml} ; \mathrm{n}=33 ; 30.6 \%)$ subsets.

Clinicopathological differences between subgroups are described in Table II.

Blood loss during LT was $\leq 1,000 \mathrm{ml}$ in 30 (27.8\%), between 1,000 and $2,000 \mathrm{ml}$ in $62(57.4 \%)$, and more than $2,000 \mathrm{ml}$ in 16 patients $(14.8 \%)$, respectively.
Postoperative maximum levels of aminotransferases and CRP were significantly higher in patients with high IOBL compared to those with low IOBL (Table II).

Predictors of overall and recurrence-free long-term survival post-LT. Post-transplant overall and recurrence-free survival periods of the entire study cohort ranged from 5 to 184 (median=73.5) months and 4 to 184 (median=68.5) months.

The 3- and 5-year overall and recurrence-free survival rates were $82.4 \%$ and $74.7 \%$, and $77.4 \%$ and $75.3 \%$, respectively, for the entire cohort.

Among patients with high IOBL, overall survival probabilities were $60.6 \%$ and $51.5 \%$ at 3 and 5 years postLT and, thus, significantly worse compared to those with low IOBL $(94.7 \%, 85 \% ; p=0.002$; Figure 1A).

Recurrence-free survival rates at 3 and 5 years were $91.9 \%$ and $91.9 \%$ in the low IOBL subset, but only $43.9 \%$ and $37.1 \%$ in the high IOBL subgroup ( $p<0.001$; Figure 1B). They were $100 \%$ and $100 \%$ in those with IOBL $\leq 1,000 \mathrm{ml}$, $81.8 \%$ and $80.1 \%$ in those with IOBL $1,000-2,000 \mathrm{ml}$ $(p=0.01)$, and $18.8 \%$ and $12.5 \%$ in patients with IOBL $>2,000 \mathrm{ml}(p<0.001$; Figure 1C), respectively.

Twenty-six liver recipients (24.1\%) developed HCC recurrence after a median of 10.5 (range=4-55) months. The mean IOBL was 2,214.7 ml (median=2,500 ml; range: 1,150 $4,000 \mathrm{ml}$ ) among patients with $\mathrm{HCC}$ relapse, but only $1,317.6 \mathrm{ml}$ (median $=1,200 \mathrm{ml}$; range $=800-2,000 \mathrm{ml})$ in those without tumor recurrence $(p<0.001)$. Only six patients with low (4\%) but 20 patients with high IOBL (60.6\%) developed HCC relapse $(p<0.001)$.

Tumor recurrence rates were $0 \%, 19.4 \%$ and $87.5 \%$ in patients with IOBL $\leq 1,000 \mathrm{ml}, 1,000-2,000 \mathrm{ml}$, and $>2,000$ $\mathrm{ml}(p<0.001)$, respectively.

Multivariate predictors of overall survival are demonstrated in Table III and include PET- status, well/moderate grading, AFP level $\leq 400 \mathrm{ng} / \mathrm{ml}$, and solitary tumor manifestation Although IOBL was a strong univariate parameter, it did not remain as a significant factor on multivariate investigation (Table III).

In contrast, IOBL $\leq 1,500 \mathrm{ml}$ was identified as an independent promoter of recurrence-free survival, along with $\mathrm{PET}^{-}$status, well/moderate tumor differentiation, and AFP level $\leq 400 \mathrm{ng} / \mathrm{ml}$ (Table IV).

Stratification according to the Milan status. Three and 5-year overall survival rates were $89.4 \%$ and $81.7 \%$ in Milan In patients, and $71.4 \%$ and $63.9 \%$ in patients with Milan Out HCC $(p=0.005)$. Corresponding recurrence-free survival rates were $86.2 \%$ and $86.2 \%$ among patients meeting, and $63.6 \%$ and $57.4 \%$ in those exceeding the Milan criteria $(p=0.001)$.

In the Milan In subgroup, AFP level and PET status were found to have an independent prognostic impact on tumorspecific outcome (Table V). 
Table II. Clinicopathological characteristics of patients according to intraoperative blood loss (IOBL) ( $n=108)$.

\begin{tabular}{|c|c|c|c|}
\hline Variable & $\begin{array}{c}\mathrm{IOBL} \leq 1500 \mathrm{ml} \\
(\mathrm{n}=75)\end{array}$ & $\begin{array}{c}\text { IOBL }>1500 \mathrm{ml} \\
(\mathrm{n}=33)\end{array}$ & $p$-Value \\
\hline Age of recipient $>60$ years & $31(41.3 \%)$ & $19(57.6 \%)$ & 0.119 \\
\hline Male gender, $\mathrm{n}(\%)$ & $40(53.3 \%)$ & $25(75.8 \%)$ & 0.028 \\
\hline Viral disease, $\mathrm{n}(\%)$ & $24(32 \%)$ & $6(18.2 \%)$ & 0.140 \\
\hline Child-Pugh B or C, n (\%) & $43(57.3 \%)$ & $15(45.5 \%)$ & 0.254 \\
\hline MELD score >20, n (\%) & $23(30.7 \%)$ & $8(24.2 \%)$ & 0.497 \\
\hline Ascites prior to $\mathrm{LT}, \mathrm{n}(\%)$ & $45(60 \%)$ & $20(60.6 \%)$ & 0.953 \\
\hline Gastrointestinal bleeding prior to LT, n (\%) & $12(16 \%)$ & $8(24.2 \%)$ & 0.301 \\
\hline AFP level at $\mathrm{LT}>400 \mathrm{ng} / \mathrm{ml}, \mathrm{n}(\%)$ & $6(8 \%)$ & $9(27.3 \%)$ & 0.008 \\
\hline TACE prior to $\mathrm{LT},(\%)$ & $51(68 \%)$ & $17(51.5 \%)$ & 0.102 \\
\hline Multiple HCC nodules, $\mathrm{n}(\%)^{*}$ & $33(44 \%)$ & $19(57.6 \%)$ & 0.139 \\
\hline Maximum $\mathrm{HCC}$ nodule size $>5 \mathrm{~cm}, \mathrm{n}(\%)^{*}$ & $10(13.3 \%)$ & $7(21.2 \%)$ & 0.300 \\
\hline Total tumor diameter $>10 \mathrm{~cm}, \mathrm{n}(\%)^{*}$ & $9(12 \%)$ & $6(18.2 \%)$ & 0.392 \\
\hline Number of HCC nodules $>3, \mathrm{n}(\%)^{*}$ & $9(12 \%)$ & $7(21.2 \%)$ & 0.214 \\
\hline Milan Out HCC, n (\%)* & $23(30.7 \%)$ & $19(57.6)$ & 0.008 \\
\hline $\mathrm{PET}^{+} \mathrm{HCC}, \mathrm{n}(\%)$ & $18(24 \%)$ & $22(60.6 \%)$ & $\leq 0.001$ \\
\hline Donor age $>50$ years, $\mathrm{n}(\%)$ & $41(54.7 \%)$ & $17(51.5 \%)$ & 0.762 \\
\hline Operation time $>350 \mathrm{~min}, \mathrm{n}(\%)$ & $41(54.7 \%)$ & $21(63.6 \%)$ & 0.385 \\
\hline Total ischemia time $>450 \mathrm{~min}, \mathrm{n}(\%)$ & $20(26.7 \%)$ & $21(63.6 \%)$ & $\leq 0.001$ \\
\hline Red blood cell units $>3, \mathrm{n}(\%)$ & $15(20 \%)$ & $24(72.7 \%)$ & $\leq 0.001$ \\
\hline Microvascular invasion, $\mathrm{n}(\%)$ & $21(28 \%)$ & $21(63.6 \%)$ & $\leq 0.001$ \\
\hline Poor tumor differentiation, $\mathrm{n}(\%)$ & $9(12 \%)$ & $12(36.4 \%)$ & 0.003 \\
\hline Post-LT peak AST level (IU/ml) & $637.2 \pm 207.4$ & $728.1 \pm 173.2$ & 0.03 \\
\hline Post-LT peak ALT (IU/ml ) & $598.6 \pm 141.8$ & $698.6 \pm 180.1$ & 0.002 \\
\hline
\end{tabular}

MELD: Model for end-stage liver disease; LT: liver transplantation; AFP: alpha fetoprotein; TACE: transarterial chemoembolization; HCC: hepatocellular carcinoma; PET $^{+}$: positron-emission tomography-positive; AST: aspartate aminotransferase; ALT: alanine aminotransferase. *According to pretransplant radiographic staging.

Among Milan Out patients, low IOBL was identified as a significant and independent prognosticator of recurrence-free survival, along with well/moderate tumor differentiation, and administration of $\leq 3 \mathrm{RBC}$ units (Table I).

The 3- and 5-year recurrence-free survival rates were $82.6 \%$ and $82.6 \%$ in Milan Out patients with low IOBL, which was not different from that of Milan In patients ( $86.2 \%$ and $86.2 \%$, respectively; log-rank $p=0.679$ ), but was significantly greater than that for Milan Out patients with high IOBL (33.8\% and $25.4 \%$, respectively; Figure 2).

Stratification according to PET status. The 3- and 5-year overall survival rates were significantly higher in PETpatients $(97.1 \%, 90.9 \%)$ than in patients with PET+ HCC (65.5\% and $47.5 \%$, respectively; $p<0.001)$. Recurrence-free survival rates at 3 and 5 years were $95.6 \%$ and $95.6 \%$ in patients with PET $^{-}$HCC, but only $45 \%$ and $39.1 \%$ in those with PET+ tumors $(p<0.001)$.

In the subgroup of PET- patients, the AFP level and MVI remained as significant prognosticators of recurrence-free survival in multivariate analysis. In contrast, only IOBL $\leq 1,500 \mathrm{ml}$ and administration of $\leq 3 \mathrm{RBC}$ units were identified as significant and independent predictors of recurrence-free survival in the subset of PET+ patients (Table VI).

The 3- and 5-year recurrence-free survival rates were $72.4 \%$ and $72.4 \%$ among PET $^{+}$patients with low IOBL, but only $20.2 \%$ and $0 \%$ in those with high IOBL (log-rank $p<0.001$; Figure 3), respectively.

\section{Discussion}

We were able to demonstrate that increased intraoperative bleeding is a strong risk factor for HCC recurrence in LT patients. Interestingly, this prognostic effect was pronounced in patients with unfavorable tumor biology, such as HCC exceeding the Milan criteria and $\mathrm{PET}^{+}$tumors. In contrast, parameters of tumor macromorphology had no independent prognostic value, which was another noteworthy result of our study.

Despite recent advancements in surgical techniques and anesthesiological care, LT is still a very complex procedure that may be associated with significant bleeding propensity (30).

In recent years, several studies have demonstrated that increased IOBL correlates significantly with poor prognosis 

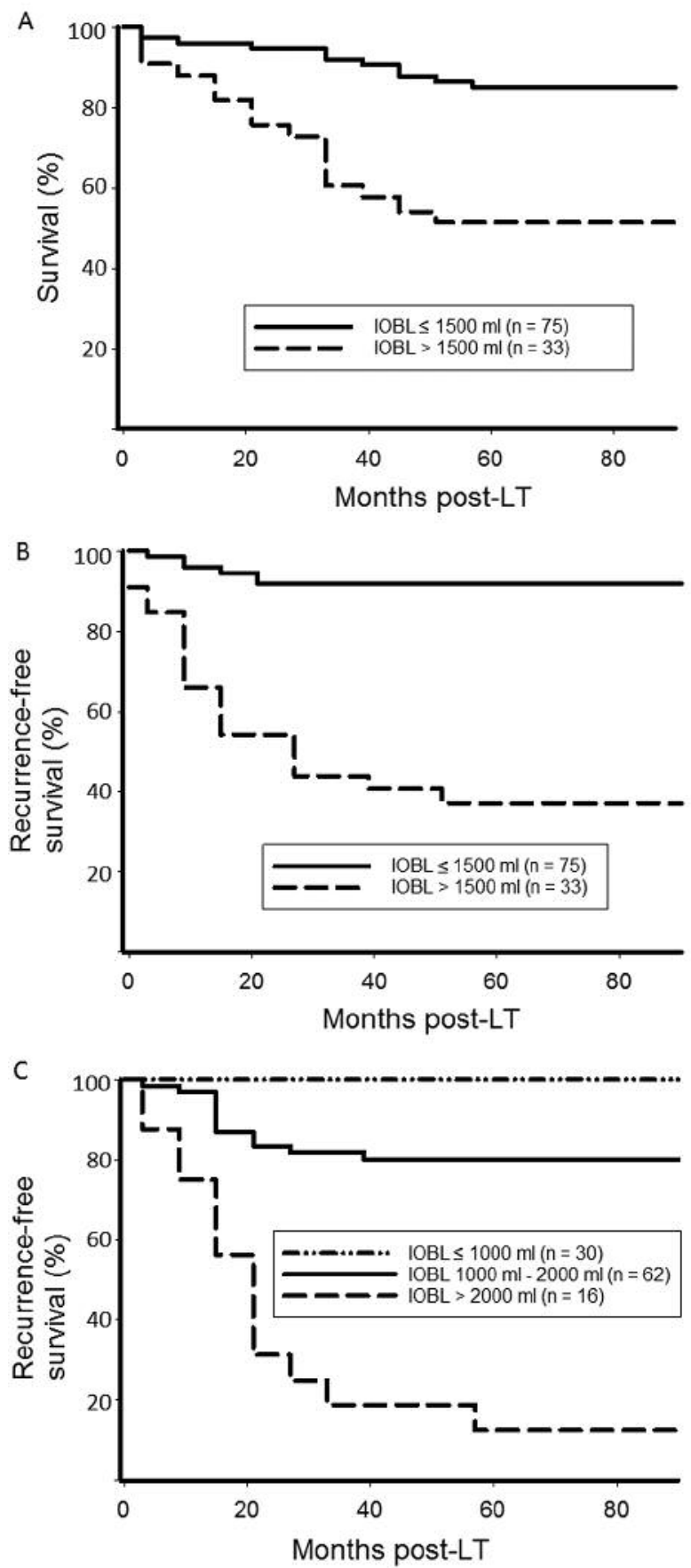

Figure 1. Kaplan-Meier curves depicting the impact of intraoperative blood loss (IOBL) on overall and recurrence-free survival post-liver transplant (LT). A: Overall survival at 3 and 5 years post-LT was significantly higher in patients with low $(94.7 \%$ and $85 \%$, respectively) compared to those with high IOBL $(60.6 \%$ and $51.5 \%$, respectively; logrank $p=0.002)$. B: Recurrence-free survival rates at 3 and 5 years were $91.9 \%$ and $91.9 \%$, respectively in patients with $I O B L \leq 1,500 \mathrm{ml}$, and $43.9 \%$ and $37.1 \%$ respectively in those with $I O B L>1,500 \mathrm{ml}$ (log-rank $p<0.001)$. C: Recurrence-free survival rates at 3 and 5 years were $100 \%$ and $100 \%$, respectively in those with $\mathrm{IOBL} \leq 1,000 \mathrm{ml}, 81.8 \%$ and $80.1 \%$ in IOBL $1,000-2,000 \mathrm{ml}(p=0.01)$, and $18.8 \%$ and $12.5 \%$, respectively, in those with $I O B L>2,000 \mathrm{ml}$ ( $\log$-rank $p<0.001)$.

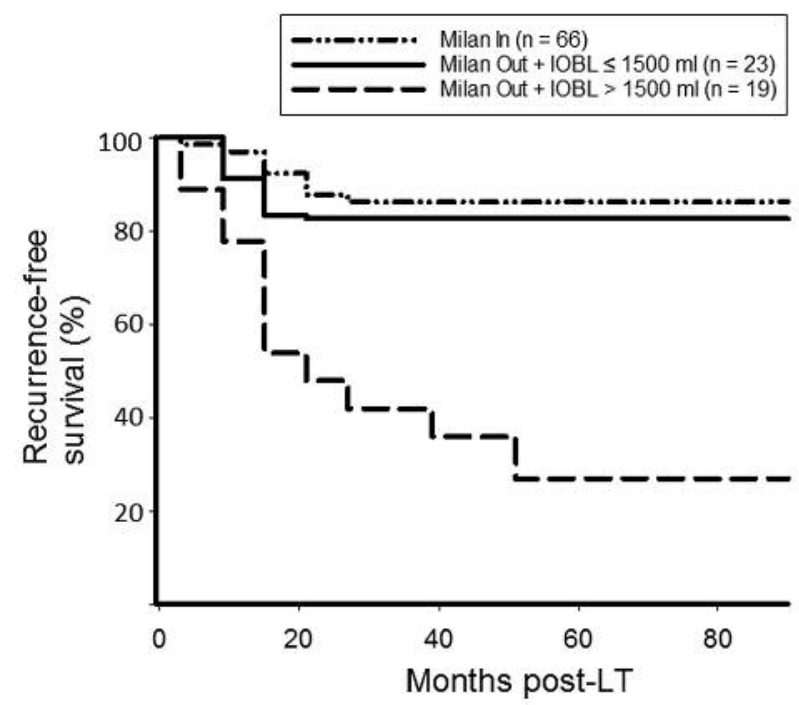

Figure 2. Kaplan-Meier curves depicting the impact of intraoperative blood loss (IOBL) on post-transplant recurrence-free survival stratified according to the Milan criteria. Milan Out patients with low IOBL had a 3-and 5-year recurrence-free survival probability (82.6\% and 82.6\%, respectively) that was not different from that of Milan In patients $(86.2 \%$ and $86.2 \%$, respectively; log-rank $p=0.433$ ), but was significantly higher than that in Milan Out patients with increased IOBL (39.5\% and $25.4 \%$, respectively; log-rank $p=0.001$ ).

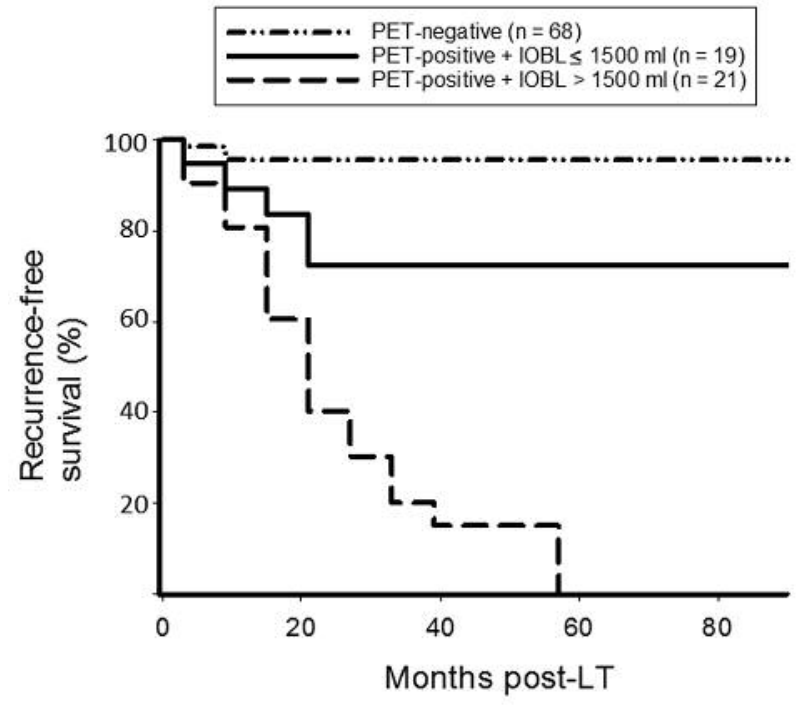

Figure 3. Kaplan-Meier curves depicting the impact of intraoperative blood loss (IOBL) on post-transplant recurrence-free survival stratified according to positron-emission tomography (PET) status. Recurrencefree survival rates at 3 and 5 years were $97.1 \%$ and $90.9 \%$ in $P E T^{-}$ patients, and $72.4 \%$ and $72.4 \%$ in $P^{2} T^{+}$patients with low IOBL ( $p=0.002$ ), but only $20.2 \%$ and $0 \%$ in $P E T^{+}$patients with IOBL $>1,500$ $m l($ log-rank $p<0.001)$. 
Table III. Prognostic variables for overall survival of the entire study group $(n=108)$.

\begin{tabular}{|c|c|c|c|}
\hline \multirow[b]{2}{*}{ Variable } & \multirow{2}{*}{$\begin{array}{c}\text { Univariate } \\
p \text {-Value }\end{array}$} & \multicolumn{2}{|c|}{ Multivariate } \\
\hline & & $\mathrm{HR}(95 \% \mathrm{CI})$ & $p$-Value \\
\hline Age of recipient ( $\leq 60$ years) & 0.246 & - & - \\
\hline Gender (female) & 0.724 & - & - \\
\hline Viral disease (none) & 0.971 & - & - \\
\hline AFP level $(\leq 400 \mathrm{ng} / \mathrm{ml})$ & 0.001 & $2.38(1.131-5.016)$ & 0.022 \\
\hline TACE prior to LT (yes) & 0.377 & - & \\
\hline Multiple HCC nodules (single)* & 0.002 & $2.34(1.161-4.723)$ & 0.017 \\
\hline Maximum HCC nodule size $(\leq 5 \mathrm{~cm})^{*}$ & 0.642 & - & - \\
\hline Total tumor diameter $(\leq 10 \mathrm{~cm})^{*}$ & 0.068 & $1.60(0.408-6.266)$ & 0.501 \\
\hline Number HCC nodules $(\leq 3)^{*}$ & 0.042 & $0.62(0.144-2.719)$ & 0.531 \\
\hline Milan status (In)* & 0.006 & $1.20(0.415-3.481)$ & 0.735 \\
\hline PET status (negative) & $<0.001$ & $3.70(1.813-7.548)$ & $<0.001$ \\
\hline Intraoperative blood loss $(\leq 1,500 \mathrm{ml})$ & 0.002 & $1.21(0.541-2.706)$ & 0.643 \\
\hline Red blood cell transfusion ( $\leq 3$ units) & 0.013 & $0.93(0.364-2.386)$ & 0.882 \\
\hline Microvascular invasion (none) & $<0.001$ & $2.16(0.774-6.006)$ & 0.141 \\
\hline Differentiation (well/moderate) & $<0.001$ & $3.36(1.654-6.835)$ & 0.001 \\
\hline
\end{tabular}

AFP: Alpha fetoprotein; TACE: transarterial chemoembolization; LT: liver transplantation; HCC: hepatocellular carcinoma; PET: positron-emission tomography; HR: hazard ratio; CI: confidence interval. *According to pretransplant radiographic staging.

Table IV. Prognostic variables for recurrence-free survival of the entire study group ( $n=108)$.

\begin{tabular}{|c|c|c|c|}
\hline \multirow[b]{2}{*}{ Variable } & \multirow{2}{*}{$\begin{array}{c}\text { Univariate } \\
p \text {-Value }\end{array}$} & \multicolumn{2}{|c|}{ Multivariate } \\
\hline & & HR $(95 \% \mathrm{CI})$ & $p$-Value \\
\hline Age of recipient ( $\leq 60$ years) & 0.593 & - & - \\
\hline Gender (female) & 0.508 & - & - \\
\hline Viral disease (none) & 0.144 & - & - \\
\hline AFP level $(\leq 400 \mathrm{ng} / \mathrm{ml})$ & $<0.001$ & $3.58(1.532-8.739)$ & 0.003 \\
\hline TACE prior to LT (yes) & 0.213 & - & - \\
\hline Multiple HCC nodules (single)* & 0.016 & $2.03(0.581-7.069)$ & 0.268 \\
\hline Maximum HCC nodule size $(\leq 5 \mathrm{~cm})^{*}$ & 0.071 & $1.35(0.304-6.005)$ & 0.692 \\
\hline Total tumor diameter $(\leq 10 \mathrm{~cm})^{*}$ & 0.061 & $1.08(0.274-4.224)$ & 0.917 \\
\hline Number HCC nodules $(\leq 3)^{*}$ & 0.089 & $0.30(0.054-1.716)$ & 0.177 \\
\hline Milan status (In)* & 0.001 & $3.24(0.719-14.585)$ & 0.126 \\
\hline PET status (negative) & $<0.001$ & $7.86(2.232-27.791)$ & 0.001 \\
\hline Intraoperative blood loss $(\leq 1,500 \mathrm{ml})$ & $<0.001$ & $3.91(1.496-10.210)$ & 0.005 \\
\hline Red blood cell transfusion ( $\leq 3$ units) & $<0.001$ & $3.61(0.941-13.865)$ & 0.058 \\
\hline Microvascular invasion (none) & $<0.001$ & $2.69(0.787-23.199)$ & 0.101 \\
\hline Differentiation (well/moderate) & $<0.001$ & $3.94(1.730-8.972)$ & 0.001 \\
\hline
\end{tabular}

AFP: Alpha fetoprotein; TACE: transarterial chemoembolization; LT: liver transplantation; HCC: hepatocellular carcinoma; PET: positron-emission tomography; HR: hazard ratio; CI: confidence interval. *According to pretransplant radiographic staging.

of different tumor entities (25-27, 31, 32). Corresponding data in the setting of LT for HCC are very rare.

Teng et al. demonstrated in 2014 that intraoperative bleeding was an independent risk factor of poor outcome in 223 LT patients with HCC, however, withou treporting on the tumor recurrence rate (33). Recently, Liu et al. from the same transplant group found that excessive blood loss (>4 1) is associated with early HCC recurrence (34). Although we used a significantly lower cut-off value, our study supports what has been reported by Liu et al., namely that enhanced intraoperative bleeding portends oncological risk in LT patients with HCC. As shown in Figure 1C, our results additionally suggest that IOBL affects the risk of HCC relapse in a 'dose-response' relationship. 
Table V. Prognostic variables for recurrence-free survival according to Milan criteria.

\begin{tabular}{|c|c|c|c|c|c|c|}
\hline \multirow[b]{3}{*}{ Variable } & \multicolumn{2}{|c|}{ Milan In (n=66) } & \multicolumn{4}{|c|}{ Milan Out $(\mathrm{n}=42)$} \\
\hline & \multirow{2}{*}{$\begin{array}{c}\text { Univariate } \\
p \text {-Value }\end{array}$} & \multicolumn{2}{|c|}{ Multivariate } & \multirow{2}{*}{$\begin{array}{l}\text { Univariate } \\
p \text {-Value }\end{array}$} & \multicolumn{2}{|c|}{ Multivariate } \\
\hline & & HR $(95 \% \mathrm{CI})$ & $p$-Value & & HR $(95 \% \mathrm{CI})$ & $p$-Value \\
\hline Age of recipient ( $\leq 60$ years) & 0.267 & & & 0.924 & & \\
\hline Gender (female) & 0.824 & & & 0.361 & & \\
\hline Viral disease (none) & 0.348 & & & 0.929 & & \\
\hline AFP level $(\leq 400 \mathrm{ng} / \mathrm{ml})$ & $<0.001$ & $21.77(3.371-140.539)$ & 0.001 & 0.095 & $1.23(0.321-47.876)$ & 0.271 \\
\hline TACE prior to LT (yes) & 0.495 & & & 0.323 & & \\
\hline Multiple HCC nodules (single)* & 0.1 & & & 0.838 & & \\
\hline Maximum HCC nodule size $(\leq 5 \mathrm{~cm}) *$ & - & & & 0.997 & & \\
\hline Total tumor diameter $(\leq 10 \mathrm{~cm})^{*}$ & - & & & 0.906 & & \\
\hline Number HCC nodules $(\leq 3)^{*}$ & 0.700 & & & 0.862 & & \\
\hline Milan status $(\mathrm{In})^{*}$ & - & & & ----- & & \\
\hline PET status (negative) & $<0.001$ & $27.58(3.244-234.515)$ & 0.002 & 0.001 & $1.72(2.676-91.815)$ & 0.189 \\
\hline Intraoperative blood loss $(\leq 1,500 \mathrm{ml})$ & $<0.001$ & $3.40(0.305-37.847)$ & 0.320 & 0.002 & $3.66(1.138-11.766)$ & 0.029 \\
\hline Red blood cell transfusion ( $\leq 3$ units) & 0.001 & $0.80(0.252-71.315)$ & 0.652 & $<0.001$ & $4.98(1.442-17.185)$ & 0.011 \\
\hline Microvascular invasion (none) & $<0.001$ & $0.99(0.328-99.138)$ & 0.319 & 0.001 & $2.60(0.081-88.682)$ & 0.107 \\
\hline Differentiation (well/moderate) & 0.004 & $1.60(0.079-2.835)$ & 0.206 & $<0.001$ & $4.01(0.070-228.013)$ & $<0.001$ \\
\hline
\end{tabular}

AFP: Alpha fetoprotein; TACE: transarterial chemoembolization; LT: liver transplantation; HCC: hepatocellular carcinoma; PET: positron-emission tomography; HR: hazard ratio; CI: confidence interval. *According to pretransplant radiographic staging.

Table VI. Prognostic variables for recurrence-free survival according to positron-emission tomography (PET) status.

\begin{tabular}{|c|c|c|c|c|c|c|}
\hline \multirow[b]{3}{*}{ Variable } & \multicolumn{2}{|c|}{ PET $-(n=68)$} & \multicolumn{4}{|c|}{$\mathrm{PET}+(\mathrm{n}=40)$} \\
\hline & \multirow{2}{*}{$\begin{array}{l}\text { Univariate } \\
p \text {-Value }\end{array}$} & \multicolumn{2}{|c|}{ Multivariate } & \multirow{2}{*}{$\begin{array}{l}\text { Univariate } \\
p \text {-Value }\end{array}$} & \multicolumn{2}{|c|}{ Multivariate } \\
\hline & & $\mathrm{HR}(95 \% \mathrm{CI})$ & $p$-Value & & $\mathrm{HR}(95 \% \mathrm{CI})$ & $p$-Value \\
\hline Age of recipient ( $\leq 60$ years) & 0.348 & & & 0.357 & & \\
\hline Gender (female) & 0.170 & & & 0.579 & & \\
\hline Viral disease (none) & 0.218 & & & 0.236 & & \\
\hline AFP level $(\leq 400 \mathrm{ng} / \mathrm{ml})$ & $<0.001$ & $3.96(0.009-108.330)$ & 0.047 & 0.005 & $2.63(1.606-8.458)$ & 0.104 \\
\hline TACE prior to LT (yes) & 0.008 & $1.40(0.060-16.731)$ & 0.237 & 0.411 & & \\
\hline Multiple HCC nodules (single)* & 0.388 & & & 0.163 & & \\
\hline Maximum HCC nodule size $(\leq 5 \mathrm{~cm})^{*}$ & 0.193 & & & 0.916 & & \\
\hline Total tumor diameter $(\leq 10 \mathrm{~cm})^{*}$ & 0.555 & & & 0.346 & & \\
\hline Number HCC nodules $(\leq 3)^{*}$ & 0.555 & & & 0.563 & & \\
\hline Milan status $(\mathrm{In})^{*}$ & 0.125 & & & 0.324 & & \\
\hline PET status (negative) & 0.014 & $1.19(0.015-66.363)$ & 0.276 & 0.008 & $4.13(1.482-11.524)$ & 0.007 \\
\hline Intraoperative blood loss $(\leq 1,500 \mathrm{ml})$ & $<0.001$ & $1.39(0.026-39.183)$ & 0.237 & 0.012 & $2.98(1.071-8.280)$ & 0.037 \\
\hline Red blood cell transfusion ( $\leq 3$ units) & $<0.001$ & $5.26(0.021-47.267)$ & 0.022 & 0.399 & & \\
\hline Microvascular invasion (none) & $<0.001$ & $2.12(0.010-96.731)$ & 0.090 & 0.033 & $2.11(0.502-9.456)$ & 0.146 \\
\hline
\end{tabular}

AFP: Alpha fetoprotein; TACE: transarterial chemoembolization; LT: liver transplantation; HCC: hepatocellular carcinoma; PET+: positron-emission tomography-positive; HR: hazard ratio; CI: confidence interval. *According to pretransplant radiographic staging.

Severe blood loss during LT worsens hepatic I/R injury (18-20). Thereby, liver graft function and early post-transplant outcome may be significantly jeopardized $(23,24)$. Currently, there is a growing body of experimental and clinical evidence that early-phase graft injury fosters late-phase HCC recurrence by induction of oxidative and pro-inflammatory actions (19-22, 35, 36). For example, several studies recently found an association between prolongation of ischemia times, increased serum aminotransferases, and risk of HCC recurrence $(22,35,36)$. In the present analysis, we noted 
significantly higher peak levels of aminotransferases and CRP in the high IOBL subgroup post-LT (Table II), which seems to emphasize a pro-tumorigenic pathway via aggravated I/R injury and inflammation.

Nevertheless, the exact biological mechanisms accounting for the enhanced oncological risk observed are not yet clear. Release of cancer cells by surgical manipulation with subsequent hematogenous spread could be one important means of metastasis $(13,18,20)$. In addition, IOBL was shown to provide immunosuppressive effects by reducing natural killer cell activities and T-helper 1 lymphokines (37). In combination with post-transplant immunosuppressive therapy, this might result in a state of 'overimmunosuppression', which is known to promote tumor outgrowth (38). Furthermore, tissue ischemia itself was demonstrated to up-regulate pro-inflammatory and pro-angiogenic factors (hypoxia-inducible factor $1 \alpha$, vascular endothelial growth factor), adhesion molecules (E-selectin, tumor-necrosis factor $\alpha$ ), chemokines (interferon- $\gamma$-induced protein 10) and matrix metalloproteinases (MMP, MMP-10) (18-20, 39-42). Additional molecular studies are necessary to further evaluate the association between bleeding, inflammation and cancer progression.

In our series, IOBL was identified as an independent risk factor in patients with Milan Out HCC but not in those with tumors meeting the standard criteria (Table V). However, recurrence-free survival in Milan Out patients with low IOBL was excellent and not different from that of Milan In patients. In contrast, 3- and 5-year recurrence-free survival rates were only $33.8 \%$ and $25.4 \%$ in Milan Out patients where IOBL exceeded $1500 \mathrm{ml}$ (Figure 2). In this setting, we speculate that minimizing intraoperative bleeding might be a crucial approach for improving outcome in LT patients with HCC exceeding the Milan criteria.

In this context, it is important to emphasize that although the Milan criteria are still standard for selecting LT candidates, it is vascular infiltration rather than macromorphology of the tumor that correlates with the presence of circulating cancer cells and risk of HCC relapse $(3,8,12,13)$. Assuming occult tumor cells to be the trigger for promoting post-LT metastasis (18), an adverse prognostic impact of IOBL should be particularly evident in patients with vascular tumor invasion. Indeed, Liu et al. have shown that excessive intraoperative bleeding is independently associated with HCC relapse in patients with, but not in those without, tumor infiltration into the vascular system (34). However, the clinical utility of this interesting finding was rather limited, since data were based on (post-transplant available) histopathological analysis not on (pretransplant available) radiographic staging (34). While macrovascular tumor invasion can be visualized on radiographic imaging and generally excludes patients from LT, MVI may not reliably be assessed by clinical staging or tumor biopsy (3,
4, 8). In previous studies, increased 18F-FDG tumor uptake on pretransplant PET was shown to correlate with aggressive HCC phenotypes, such as MVI and poor grading (14-16). In order to preoperatively identify subgroups at risk for procancerogenic efficts caused by IOBL, we therefore stratified our data according to PET results and not to histopathological tumor features.

Despite an overall poor prognosis for $\mathrm{PET}^{+} \mathrm{HCC}$ following LT, a subset of our $\mathrm{PET}^{+}$study patients demonstrated a meaningful tumor-specific outcome, particularly those with low IOBL. In contrast, none of the PET + patients in the high IOBL subgroup was alive without tumor relapse at 5 years post-LT (Figure 3). Apart from this, increased IOBL was identified as the most powerful risk factor for tumor relapse in this subset of patients (Table VI). This interesting result of our study indirectly corroborates the findings by Liu et al. (34), however, on the basis of pretransplant clinical staging and not on histopathological assessment. Additionally, it clearly points out that the combination of metabolic tumor aggressiveness and increased intraoperative bleeding produces an extraordinary oncological risk and should therefore be avoided.

Numerous previous studies have reported that the administration of blood products promotes the risk of $\mathrm{HCC}$ recurrence following surgical treatment of $\mathrm{HCC}$ due to immunomodulatory and immunosuppressive effects. However, currently available data remain inconclusive, mainly since the transfusion policy varied among the studies and blood loss was frequently not included in the analysis (25-27, 43-45). In our series, RBC transfusion did not remain as a significant risk factor on multivariate investigation of the entire study cohort (Tables III and IV). We, therefore, suppose bleeding as the 'transfusion-promoting' process to be more sensitive in this clinical setting than administration of RBC units. Interestingly, it turned out to be an independent risk factor in subsets of aggressive tumor features (Tables V and VI). If this was really a causal effect, or whether instead this has to be assessed as a result of IOBL remains unclear. In any case, it seems obvious that limitation of bleeding tendency will reduce transfusion requirements and subsequent harmful modulation of the immune system

To further clarify the clinical implications of our results, prospective multicenter studies should be performed including molecular investigations. Pending confirmation of our findings, all efforts in limiting IOBL should be made not only for reducing perioperative morbidity and mortality, but also for improving oncological outcome. Consequently, appropriate donor-recipient matching, improved allocation logistics, reduced ischemia times and optimized surgical techniques $(18,22,35,36)$ might be especially considered in patients with unfavorable tumor characteristics.

Our study has several limitations. Firstly, it was retrospective in nature with limitations of an observational 
data analysis. But for ethical reasons, it seems to be impossible to conduct a randomized prospective study on this sensitive topic. Secondly, we used a threshold for IOBL that was based on the mean and median values, since receiver operating characteristics curve analysis was not applicable. Furthermore, a selection bias cannot be excluded, as there were significant differences in tumor characteristics between the subgroups (Table II). However, these differences could be a result of more demanding surgical procedures in patients with advanced tumor stages (26). Apart from this, aggressive tumor biology may in turn induce proinflammatory and oxidative mechanisms, possibly aggravating bleeding propensity (46). This issue needs to undergo further experimental and clinical studies.

In summary, our study demonstrated that enhanced IOBL appears to promote HCC recurrence following LT, particularly in patients with features of aggressive tumor biology. In order to improve prognosis in LT patients with advanced HCC, intraoperative bleeding must be minimized. Our results imply additionally that IOBL should be incorporated into the assessment of the individual posttransplant oncological risk profile.

\section{Conflicts of Interest}

The Authors declare that there are no competing conflicts of interest in regard to this study. There was no funding related to the study.

\section{References}

1 Tabrizian P, Jibara G, Shrager B, Schwartz M and Roayaie S: Recurrence of hepatocellular cancer after resection: patterns, treatments, and prognosis. Ann Surg 261: 947-955, 2015.

2 Franssen B, Jibara G, Tabrizian P, Schwartz ME and Roayaie S: Actual 10-year survival following hepatectomy for hepatocellular carcinoma. HPB 16: 830-835, 2014.

3 Kornberg A: Liver transplantation for hepatocellular carcinoma beyond Milan Criteria: Multidisciplinary approach to improve outcome. ISRN Hepatology doi.org/10.1155/2014/706945, 2014.

4 Agopian VG, Harlander-Locke M, Zarrinpar A, Kaldas FM, Farmer DG, Yersiz H, Finn RS, Tong M, Hiatt JR and Busuttil RW: A novel prognostic nomogram accurately predicts hepatocellular carcinoma recurrence after liver transplantation: analysis of 865 consecutive liver transplant recipients. J Am Coll Surg 220: 416-427, 2015.

5 Mazzaferro V, Regalia E, Doci R, Andreola S, Pulvirenti A, Bozzetti F, Montalto F, Ammatuna M, Morabito A and Gennari L: Liver transplantation for the treatment of small hepatocellular carcinomas in patients with cirrhosis. N Engl J Med 334: 693699, 1996.

6 Mazzaferro V, Bhoori S, Sposito C, Bongini M, Langer M, Miceli R and Mariani L: Milan criteria in liver transplantation for hepatocellular carcinoma: an evidence-based analysis of 15 years of experience. Liver Transpl 17(Suppl 2): 44-57, 2011.

7 Herrero JI, Sangro B, Pardo F, Quiroga J, Iñarrairaegui M, Rotellar F, Montiel C, Alegre F, and Prieto J: Liver transplantation in patients with hepatocellular carcinoma across Milan criteria. Liver Transpl 3: 272-278, 2002.

8 Cillo U, Giuliani T, Polacco M, Herrero Manley LM, Crivellari $\mathrm{G}$ and Vitale A: Prediction of hepatocellular carcinoma biological behavior in patient selection for liver transplantation. World J Gastroenterol 22: 232-252, 2016.

9 Menon KV, Hakeem AR and Heaton ND: Review article: liver transplantation for hepatocellular carcinoma - a critical appraisal of the current worldwide listing criteria. Aliment Pharmacol Ther 60: 1165-1171, 2004.

10 Machado A, Kiss G, Ernani L, Marroni C, Zanotelli ML, Cantisani G, Cerski CT, Coral $G$ and Brandão A: Liver Transplantation Group. Validation of the "Metroticket" model in a cohort of patients transplanted for hepatocellular carcinoma in southern Brazil. Clin Transplant 29: 806-812, 2015.

11 Teng F, Han QC, Ding GS, Ni ZJ, Fu H, Guo WY, Shi XM, Gao $\mathrm{XG}$, Ma J and Fu ZR: Validation of a criteria-specific long-term survival prediction model for hepatocellular carcinoma patients after liver transplantation. Sci Rep 5: 1173, doi: 10.1038/srep11733, 2015.

12 Jonas S, Bechstein WO, Steinmüller T, Herrmann M, Radke C, Berg T, Settmacher U and Neuhaus P: Vascular invasion and histopathologic grading determine outcome after liver transplantation for hepatocellular carcinoma in cirrhosis. Hepatology 33: 1080-1086, 2001.

13 Zhang Y, Shi ZL, Yang X and Yin ZF: Targeting of circulating hepatocellular carcinoma cells to prevent postoperative recurrence and metastasis. World J Gastroenterol 20: 142-147, 2014.

14 Bailly M, Venel Y, Orain I, Salamé E and Ribeiro MJ: 18F-FDG PET in liver transplantation setting of hepatocellular carcinoma: predicting histology? Clin Nucl Med 41: 126-129, 2016.

15 Kornberg A, Freesmeyer M, Bärthel E, Jandt K, Katenkamp K, Steenbeck J, Sappler A, Habrecht O, Gottschild D and Settmacher U: 18F-FDG-uptake of hepatocellular carcinoma on PET predicts microvascular tumor invasion in liver transplant patients. Am J Transplant 9: 592-600, 2009.

16 Yang SH, Suh KS, Lee HW, Cho EH, Cho JY, Cho YB, Yi NJ and Lee KU: The role of (18)F-FDG-PET imaging for the selection of liver transplantation candidates among hepatocellular carcinoma patients. Liver Transpl 11: 1655-1660, 2006.

$17 \mathrm{Gu}$ XQ, Zheng WP, Teng DH, Sun JS and Zheng H: Impact of non-oncological factors on tumor recurrence after liver transplantation in hepatocellular carcinoma patients. World J Gastroenterol 22: 2749-2759, 2016.

18 Toso C, Mentha G and Majno P: Liver transplantation for hepatocellular carcinoma: five steps to prevent recurrence. Am J Transplant 11: 2031-2035, 2011.

19 Orci LA, Berney T, Majno PE, Lacotte S, Oldani G, Morel P, Mentha $G$ and Toso $C$ : Donor characteristics and risk of hepatocellular carcinoma recurrence after liver transplantation. Br J Surg 102: 1250-1257, 2015.

20 Orci LA, Lacotte S, Oldani G, Morel P, Mentha G and Toso C: The role of hepatic ischemia-reperfusion injury and liver parenchymal quality on cancer recurrence. Dig Dis Sci 59: 20582068, 2014.

21 Oldani G, Crowe LA, Orci LA, Slits F, Rubbia-Brandt L, de Vito C, Morel P, Mentha G, Berney T, Vallée JP, Lacotte S and Toso $\mathrm{C}$ : Pre-retrieval reperfusion decreases cancer recurrence after rat ischemic liver graft transplantation. J Hepatol 61: 278-285, 2014. 
22 Kornberg A, Witt U, Kornberg J, Friess $\mathrm{H}$ and Thrum K: Extended ischemia times promote risk of $\mathrm{HCC}$ recurrence in liver transplant patients. Dig Dis Sci 60: 2832-2839, 2015.

23 Nastos C, Kalimeris K, Papoutsidakis N, Tasoulis MK, Lykoudis PM, Theodoraki K, Nastou D, Smyrniotis V and Arkadopoulos $\mathrm{N}$ : Global consequences of liver ischemia/reperfusion injury. Oxid Med Cell Longev doi: 10.1155/2014/906965, 2014.

24 Zhai Y, Petrowsky H, Hong JC, Busuttil RW and KupiecWeglinski JW: Ischemia-reperfusion injury in liver transplantation-from bench to bedside. Nat Rev Gastroenterol Hepatol 10: 79-89, 2013.

25 Yang T, Zhang J, Lu JH, Yang GS, Wu MC and Yu WF: Risk factors influencing postoperative outcomes of major hepatic resection of hepatocellular carcinoma for patients with underlying liver diseases. World J Surg 35: 2073-2082, 2011.

26 Katz SC, Shia J, Liau KH, Gonen M, Ruo L, Jarnagin WR, Fong Y, D'Angelica MI, Blumgart LH and Dematteo RP: Operative blood loss independently predicts recurrence and survival after resection of hepatocellular carcinoma. Ann Surg 249: 617-623, 2009.

27 Nanashima A, Abo T, Hamasaki K, Wakata K, Tominaga T, Hidaka S, Takeshita $\mathrm{H}$ and Nagayasu T. Perioperative nontumorous factors associated with survival in HCC patients who underwent hepatectomy. Anticancer Res 31: 4545-4551, 2011.

28 Tilg H, Nordberg J, Vogel W, Luger TA, Herold M, Aulitzky WE, Margreiter R and Huber C: Circulating serum levels of interleukin 6 and C-reactive protein after liver transplantation. Transplantation 54: 142-146, 1992.

29 Kornberg A, Witt U, Kornberg J, Müller K, Friess H and Thrum $\mathrm{K}$ : Postoperative peak serum C-reactive protein is a predictor of outcome following liver transplantation for hepatocellular carcinoma. Biomarkers 8: 1-8, 2015.

30 Feltracco P, Brezzi M, Barbieri S, Galligioni H, Milevoj M, Carollo $\mathrm{C}$ and Ori C: Blood loss, predictors of bleeding, transfusion practice and strategies of blood cell salvaging during liver transplantation. World J Hepatol 5: 1-15, 2013.

31 Okamura R, Hida K, Hasegawa S, Sakai Y, Hamada M, Yasui M and Hinoi T, Watanabe M; Japan Society of Laparoscopic Colorectal Surgery: Impact of intraoperative blood loss on morbidity and survival after radical surgery for colorectal cancer patients aged 80 years or older. Int J Colorectal Dis 31: 327-334, 2016.

32 Jiang N, Deng JY, Ding XW, Zhang L, Liu HG, Liang YX and Liang H: Effect of complication grade on survival following curative gastrectomy for carcinoma. World J Gastroenterol 20: 8244-8252, 2014.

33 Teng F, Wang GH, Tao YF, Guo WY, Wang ZX, Ding GS, Shi $\mathrm{XM}$ and Fu ZR: Criteria-specific long-term survival prediction model for hepatocellular carcinoma patients after liver transplantation. World J Gastroenterol 20: 10900-10907, 2014.

34 Liu B, Teng F, Fu H, Guo WY, Shi XM, Ni ZJ, Gao XG, Ma J, $\mathrm{Fu} \mathrm{ZR}$ and Ding GS: Excessive intraoperative blood loss independently predicts recurrence of hepatocellular carcinoma after liver transplantation. BMC Gastroenterol 15: 138, doi: 10.1186/s12876-015-0364-5, 2015.
35 Nagai S, Yoshida A, Facciuto M, Moonka D, Abouljoud MS, Schwartz ME and Florman SS: Ischemia time impacts recurrence of hepatocellular carcinoma after liver transplantation. Hepatology 61: 895-904, 2015.

36 Croome KP, Wall W, Chandok N, Beck G, Marotta P and Hernandez-Alejandro R: Inferior survival in liver transplant recipients with hepatocellular carcinoma receiving donation after cardiac death liver allografts. Liver Transpl 19: 1214-1223, 2015.

37 Angele MK and Faist E: Clinical review: immunodepression in the surgical patient and increased susceptibility to infection. Crit Care 6: 298-305, 2002.

38 Lee JY, Kim YH, Yi NJ, Kim HS, Lee HS, Lee BK, Kim H, Choi YR, Hong G, Lee $\mathrm{KW}$ and Suh KS: Impact of imunosuppressant therapy on early recurrence of hepatocellular carcinoma after liver transplantation. Clin Mol Hepatol 20: 192203, 2014.

39 Carmeliet P, Dor Y, Herbert J, Fukumura D, Brusselmans K, Dewerchin M, Neeman M, Bono F, Abramovitch R, Maxwell P, Koch CJ, Ratcliffe P, Moons L, Jain RK, Collen D and Keshert E: Role of HIF-1alpha in hypoxia-mediated apoptosis, cell proliferation and tumour angiogenesis. Nature 394: 485-49, 1998.

$40 \mathrm{Li} \mathrm{T}$, Zhu Y, Qin CYJ, Yang Z, Fang A, Xu S and Ren W: Expression and prognostic significance of vascular endothelial growth factor receptor 1 in hepatocellular carcinoma. Clin Pathol 65: 808-814, 2012.

41 Yoong KF, McNab G, Hübscher SG and Adams DH: Vascular adhesion protein-1 and ICAM-1 support the adhesion of tumorinfiltrating lymphocytes to tumor endothelium in human hepatocellular carcinoma. J Immunol 160: 3978-3988, 1998.

42 Zucker S and Vacirca J: Role of matrix metalloproteinases (MMPs) in colorectal cancer. Cancer Metastasis Rev 23: 101117, 2004.

43 Liu L, Wang Z, Jiang S, Shao B, Liu J, Zhang S, Zhou Y, Zhou $\mathrm{Y}$ and Zhang Y: Perioperative allogenenic blood transfusion is associated with worse clinical outcomes for hepatocellular carcinoma: a meta-analysis. PLoS One 8: e64261. doi: 10.1371, 2013.

44 Yang T, Lu JH, Lau WY, Zhang TY, Zhang H, Shen YN, Alshebeeb K, Wu MC, Schwartz M and Shen F: Perioperative blood transfusion does not influence recurrence-free and overall survivals after curative resection for hepatocellular carcinoma: A Propensity Score Matching Analysis. J Hepatol 64: 583-593, 2016.

45 Kwon AH, Matsui Y and Kamiyama Y: Perioperative blood transfusion in hepatocellular carcinomas: influence of immunologic profile and recurrence free survival. Cancer 91: 771-778, 2001.

46 Coussens LM and Werb Z: Inflammation and cancer. Nature 420: 860-867, 2002.
Received August 1, 2016

Revised September 6, 2016

Accepted September 12, 2016 